\title{
Immunotactoid Glomerulopathy with Nontuberculous Mycobacterial Infection: A Novel Association
}

\author{
Yoshio Shimizu $^{\text {a, b }}$ Keiichi Wakabayashia Hiroyuki Iwasakic

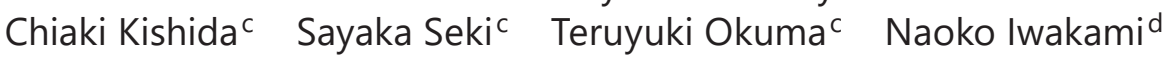 \\ Takumi Iwasawa $^{b}$ Hiroshi Maekawa ${ }^{e}$ Yasuhiko Tomino ${ }^{f}$ Ryo Wadac \\ Yusuke Suzukig \\ aDivision of Nephrology, Department of Internal Medicine, Juntendo University Shizuoka \\ Hospital, Izunokuni, Japan; bShizuoka Medical Research Center for Disaster, Juntendo \\ University, Izunokuni, Japan; 'Division of Pathology, Juntendo University Shizuoka Hospital, \\ Izunokuni, Japan; dDivision of Respiratory Medicine, Department of Internal Medicine,

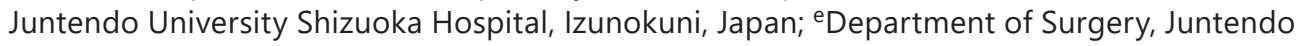 \\ University Shizuoka Hospital, Izunokuni, Japan; ${ }^{f}$ Asian Pacific Renal Research Promotion \\ Office, Medical Corporation SHOWAKI, Tokyo, Japan; 9Department of Nephrology, \\ Juntendo University Faculty of Medicine, Tokyo, Japan
}

\section{Keywords}

Immunotactoid glomerulopathy · MPGN type 3 - Nontuberculous mycobacterial infection · Novel classification of MPGN

\begin{abstract}
A 70-year-old woman underwent a renal biopsy due to nephrotic syndrome. She had suffered from nontuberculous mycobacterial infection (NTM) for 14 years. The patient was diagnosed as having membranoproliferative glomerulonephritis (MPGN) type 3 and immunoglobulin (Ig)-associated MPGN based upon LM/erythromycin and IF findings, respectively. In highmagnification imaging, electron-dense deposits showed immunotactoid glomerulopathy (ITG). There was no evidence of hematological cancer, and the patient improved after receiving treatments for NTM. To the best of our knowledge, this patient is the first to show an association between ITG and NTM. Although ITG is generally considered as related to lymphoproliferative disease, it is suggested that ITG is driven by bacterial infection and is a potential outcome of Ig-associated MPGN.
\end{abstract}




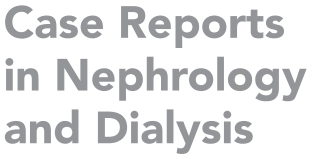

\section{Introduction}

While idiopathic membranoproliferative glomerulonephritis (MPGN) is generally limited to children and juveniles, secondary MPGN is common among the elderly [1]. Secondary MPGN is derived from various diseases, including hepatitis B or C, cryoglobulinemia, systemic lupus erythematosus (SLE), Sjögren's syndrome, and paraprotein deposition diseases [2]. Using erythromycin (EM), MPGN can be classified into MPGN type 1, type 2, and type 3 . The discovery of the role of complement in generating glomerulonephritis led to the development of a novel classification of MPGN, which was based on pathophysiology and immunofluorescence in renal biopsy specimens [3-5]. In these criteria, MPGN is divided into immunoglobulin (Ig)-associated MPGN and C3 glomerulopathy (C3-G).

Herein, we present a case of a 70 -year-old woman with nephrotic syndrome during nontuberculous mycobacterial infection (NTM). LM and EM of renal biopsy specimen findings led to the diagnosis of MPGN type 3 and IF suggested Ig-associated MPGN. In an ultrastructural survey, the electron-dense deposits (EDDs) revealed that the patient had immunotactoid glomerulopathy (ITG). MPGN associated with mycobacterial infection is rare, and this case is the first report of ITG with NTM.

\section{Case}

A 70-year-old woman was admitted to the Juntendo University Shizuoka Hospital for renal biopsy. She consulted in our outpatient clinic 2 years ago due to proteinuria and microscopic hematuria. Although she was treated with angiotensin II receptor antagonist (losartan, $25 \mathrm{mg}$ /day), the urinary protein excretion level increased to the nephrotic range, and pretibial pitting edema was observed.

The patient had suffered from NTM for 14 years. Cultures of gastric lavage samples were positive for Mycobacterium intracellulare. Since she developed toxic epidermal necrolysis after the administration of 3 antituberculosis drugs (isoniazid, rifampicin, and ethambutol), antimycobacterial treatment was suspended.

At the time of admission, the patient was an alert, well-developed, slender woman appearing her stated age. She complained that she became easily fatigued due to marked pitting edema in the lower extremities. The patient did not drink alcohol or smoke. Her blood pressure in the sitting position was 138/94 $\mathrm{mm} \mathrm{Hg}$, and the pulse rate was 70 beats per minute. Urinalysis showed a 3+ dipstick test for protein, 2+ for occult blood, and was negative for sugar. Urinary sediments showed 20-29 RBCs/HPF. The urinary protein-to-creatinine ratio was $9.9 \mathrm{~g} / \mathrm{g}$ Cr. Laboratory tests revealed serum urea nitrogen 24.7 (normal values: 9-21) $\mathrm{mg} / \mathrm{dL}$, creatinine 1.43 (normal range: $0.4-0.9$ ) $\mathrm{mg} / \mathrm{dL}$, uric acid 7.3 (normal range: 3.8-7.5) $\mathrm{mg} / \mathrm{dL}$, and an eGFR of $28.6 \mathrm{~mL} / \mathrm{min} / 1.73 \mathrm{~m}^{2}$ (based upon the serum creatinine). The hematologic evaluation, liver function, serum cholesterol, and electrolytes were within normal ranges. Serological markers for syphilis and hepatitis B and hepatitis C were all negative. Serum immunoelectrophoresis revealed normal IgG, IgA, and IgM precipitin arcs. Tests for antinuclear antibodies, anti-DNA antibodies, PR3-ANCA, MPO-ANCA, and antiglomerular basement membrane antibodies were negative. Testing for cryoglobulins was also negative. The C3 and C4 levels were within normal ranges (Table 1). Small nodular opacities were observed in chest radiography, and multiple small nodules and multifocal bronchiectasis with small cavities were observed in computed tomography imaging (Fig. 1a, b).

During renal biopsy, 3 cores were obtained by ultrasound-guided needle biopsy. The renal cortex was approximately $70 \%$. LM showed 21 glomeruli that exhibited mesangial widening and thickening of capillary walls. Lobular accentuation was evident in the glom-

\section{Karger'}


Shimizu et al.: Immunotactoid Glomerulopathy with Nontuberculous Mycobacterial Infection

Table 1. Results of the laboratory tests

\begin{tabular}{|c|c|c|c|c|c|}
\hline & Patient & Normal range & & Patient & Normal range \\
\hline Urinalysis & & & Chemistry & & \\
\hline SG & 1.008 & $1.015-1.025$ & T.P, g/dL & 5.7 & $6.3-7.8$ \\
\hline $\mathrm{pH}$ & 6.5 & $5.0-7.8$ & Alb, g/dL & 2.9 & $3.7-4.9$ \\
\hline Protein & $(+++)$ & $(-)$ & AST, IU/L & 43 & $11-40$ \\
\hline Occult blood & $(++)$ & $(-)$ & ALT, IU/L & 22 & $6-43$ \\
\hline Glucose & $(-)$ & $(-)$ & LDH, IU/L & 336 & $200-400$ \\
\hline $\mathrm{RBC} / \mathrm{HPF}$ & $20-29$ & $<1$ & BUN, mg/dL & 24.7 & $9-21$ \\
\hline $\mathrm{WBC} / \mathrm{HPF}$ & $>50$ & $<1-3$ & $\mathrm{Cr}, \mathrm{mg} / \mathrm{dL}$ & 1.43 & $0.4-0.9$ \\
\hline Hyaline casts/WF & $5-9$ & $<1-2$ & eGFR, ml/ & 28.6 & $>60$ \\
\hline Granular casts & $10-19$ & $(-)$ & $\min / 1.73 \mathrm{~m}^{2}$ & 7.3 & $3.8-7.5$ \\
\hline Protein, g/gCr & 9.9 & $<0.05$ & $\mathrm{UA}, \mathrm{mg} / \mathrm{dL}$ & 140 & $135-145$ \\
\hline NAG, IU/L & 20.2 & $0.7-11.2$ & $\mathrm{Na}, \mathrm{mEq} / \mathrm{L}$ & 4.2 & $3.5-4.9$ \\
\hline$\beta 2$-microglobulin, $\mu \mathrm{g} / \mathrm{L}$ & 2,990 & $<230$ & $\mathrm{~K}, \mathrm{mEq} / \mathrm{L}$ & 105 & $96-108$ \\
\hline Peripheral blood & & & $\mathrm{Cl}, \mathrm{mEq} / \mathrm{L}$ & 8.6 & $8.5-10.5$ \\
\hline $\mathrm{WBC} / \mu \mathrm{L}$ & 6,100 & $4,700-8,700$ & $\mathrm{Ca}, \mathrm{mg} / \mathrm{dL}$ & 4.1 & $2.5-4.5$ \\
\hline $\mathrm{RBC} \times 10^{4} / \mu \mathrm{L}$ & 434 & $427-500$ & $\mathrm{P}, \mathrm{mg} / \mathrm{dL}$ & & \\
\hline $\mathrm{Hb}, \mathrm{g} / \mathrm{dL}$ & 13.6 & $13.5-17.6$ & $\mathrm{CRP}, \mathrm{mg} / \mathrm{dL}$ & 0.3 & $<0.5$ \\
\hline $\mathrm{Ht}, \%$ & 41.1 & $39.8-51.8$ & HbA1c, \% & 5.7 & $<5.8$ \\
\hline $\mathrm{PLT} \times 10^{4} / \mu \mathrm{L}$ & 22.1 & $15-35$ & $\mathrm{BNP}, \mathrm{pg} / \mathrm{mL}$ & 218 & $<18.4$ \\
\hline Serology & & & Infection & & \\
\hline ANA & $<40 x$ & $<40 x$ & ТРНА & $(-)$ & $(-)$ \\
\hline $\operatorname{IgG}, \mathrm{mg} / \mathrm{dL}$ & 713 & $739-1,649$ & RPR & $(-)$ & $(-)$ \\
\hline $\operatorname{IgA}, \mathrm{mg} / \mathrm{dL}$ & 96 & $107-363$ & HbsAg & $(-)$ & $(-)$ \\
\hline $\operatorname{IgM}, \mathrm{mg} / \mathrm{dL}$ & 62 & $46-260$ & $\mathrm{HCV}$ & $(-)$ & $(-)$ \\
\hline $\mathrm{C} 3, \mathrm{mg} / \mathrm{dL}$ & 88.9 & $65-135$ & \multicolumn{2}{|c|}{ Mycobacterial culture } & \\
\hline $\mathrm{C} 4, \mathrm{mg} / \mathrm{dL}$ & 38.6 & $13-35$ & \multicolumn{2}{|c|}{ M. intracellulare (+) } & $(-)$ \\
\hline CH50, U/mL & 35 & $28-53$ & & & \\
\hline Cryoglobulin & $(-)$ & $(-)$ & & & \\
\hline MPO-ANCA, EU & $<10$ & $<10$ & & & \\
\hline PR3-ANCA, EU & $<10$ & $<10$ & & & \\
\hline M-protein & $(-)$ & & & & \\
\hline
\end{tabular}

Ig, immunoglobulin.

eruli, and the capillary lumens were collapsed. Parts of the lobular centers were sclerosed. The glomerular basement membrane was thickened, resulting in double contour appearance. Subepithelial deposition was evident (Fig. 2a, b). Two glomeruli were sclerosed globally, and focal tubular atrophy with interstitial fibrosis and inflammatory cell infiltration were observed in 30\% area of the cortex (Fig. 2c). Congo red staining of the renal tissues was negative for amyloid deposition (Fig. 2d). In IF, granular deposits of C3 and C1q were observed in the glomerular mesangial areas and capillary walls. Rather scant IgG and IgM deposits were mainly evident in the capillary walls (Fig. 3). IgA and fibrinogen showed subtle or negative signals. EM showed marked evidence of massive EDDs in the subendothelial areas and mesangial interposition (Fig. 4a). EDDs were observed in the glomerular capillary walls and subepithelial areas. The foot processes over the EDDs were effaced (Fig. 4b, c). High-magnification views revealed that the EDDs were composed of microtubules with a diameter around $50 \mathrm{~nm}$. These tubules formed parallel arrays (Fig. 4d). Immunohistochemistry with anti-DnaJ homolog subfamily B member 9 (DNAJB9) antibody, which specifically stains glomerular deposits in the patients with fibrillary glomerulonephritis, revealed background signals in 
Case Reports in Nephrology and Dialysis

\begin{tabular}{l|l}
\hline Case Rep Nephrol Dial 2021;11:136-146 \\
\hline DOI: 10.1159/000515583 & $\begin{array}{l}\text { @ 2021 The Author(s). Published by S. Karger AG, Basel } \\
\text { www.karger.com/cnd }\end{array}$ \\
\hline
\end{tabular}

Shimizu et al.: Immunotactoid Glomerulopathy with Nontuberculous Mycobacterial Infection

glomeruli, while human exocrine glands in resected pancreas showed strongly positive signals (Fig. 4e, f) [6, 7]. The findings led to the conclusion that this case was the Burkholder variant of MPGN type 3 or IgG- and C3-positive (immune complex-associated) MPGN by LM and IF [5]. The Congo red staining, immunohistochemistry with anti-DNAJB antibody, and EM findings led to the diagnosis of immunotactoid ITG [8].

M. intracellulare genomic DNA was not detectable in renal tissues from the formalinfixed, paraffin-embedded biopsy slides using PCR targeting the $16 \mathrm{~S}$ internal transcribed spacer region [9] (Fig. 4g). The pulmonologist who treated the patient administered an antibacterial agent since her breathing condition and chest X-ray worsened after the renal diagnosis was obtained. The urinary protein excretion level decreased gradually to $3.3 \mathrm{~g} / \mathrm{gCr}$, and the rate of elevation of serum creatinine was slower (Fig. 5). Although she had previously experienced allergic reactions against antibacterial agents, her renal function remained stable by adjusting her administration.

\section{Discussion}

Immune complex-associated MPGN occurs most commonly due to hepatitis B or C viral infection, which drives persistent antigenemia and immune complex formation $[4,10]$. In addition to other viruses, MPGN can be caused by infectious agents, including those of bacterial
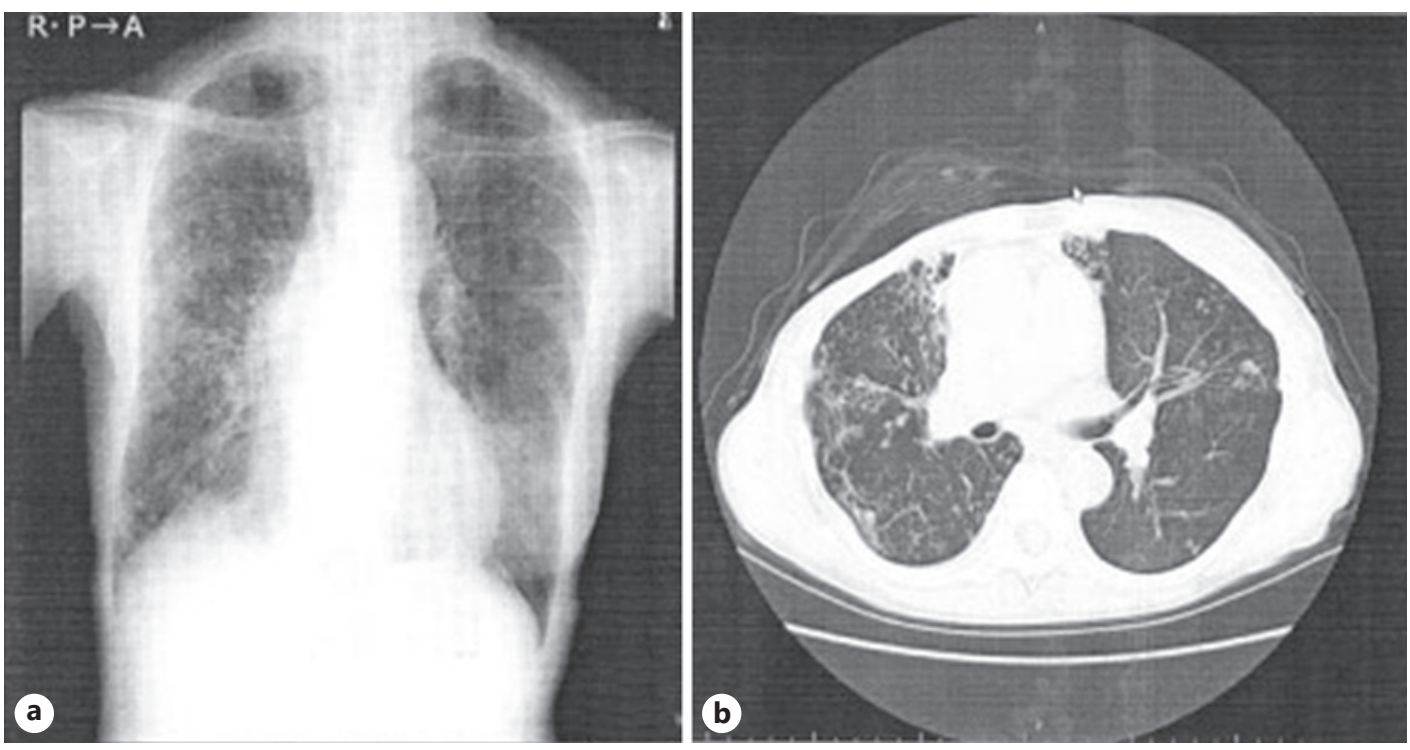

Fig. 1. Chest imaging. a Chest radiography showing bilateral infiltrates with nodular opacities. b Computed tomography revealing multiple small nodules and multifocal bronchiectasis with small cavities in both lungs.

Fig. 2. Light microscopy findings of renal biopsy specimens. a Lobular accentuation with cellular proliferation in the glomeruli (arrows) and focal tubular atrophy (PAS stain, $\times 40$ ). b MPGN type 3-like glomerulus showing cellular proliferation and mesangial widening (asterisk). The glomerular basement membranes are thickened and show double contour appearance (dagger). Subepithelial deposition is also observed (double dagger) (PASM stain, $\times 200$ ). c Global sclerosis accompanying tubulointerstitial fibrosis with cellular filtration. Thirty percent of the whole cortex is damaged (HE stain, $\times 100$ ). d Amyloid deposition is not observed (Congo red stain, $\times 100)$. e Kappa-light chain is deposited in the glomeruli $(\times 200)$. $\mathbf{f}$ Lambda-light chain is observed in the glomeruli $(\times 200)$. MPGN, membranoproliferative glomerulonephritis.

(For figure see next page.) 
Case Reports in Nephrology and Dialysis

\begin{tabular}{l|l}
\hline Case Rep Nephrol Dial 2021:11:136-146 \\
\hline DOI: 10.1159/000515583 & $\begin{array}{l}\text { @ 2021 The Author(s). Published by S. Karger AG, Basel } \\
\text { www.karger.com/cnd }\end{array}$ \\
\hline
\end{tabular}

Shimizu et al.: Immunotactoid Glomerulopathy with Nontuberculous Mycobacterial Infection

origin, as in shunt nephritis and endocarditis, and protozoal diseases of malaria and schistosomiasis $[11,12]$. MPGN is caused by circulating immune complexes associated with autoimmune diseases including mixed cryoglobulinemia, SLE, Sjögren's syndrome, and scleroderma $[5,13]$. Deposition of monoclonal Igs in the glomerular capillary walls and mesangial areas is another cause of immune complex-associated MPGN. Monoclonal [14] immune
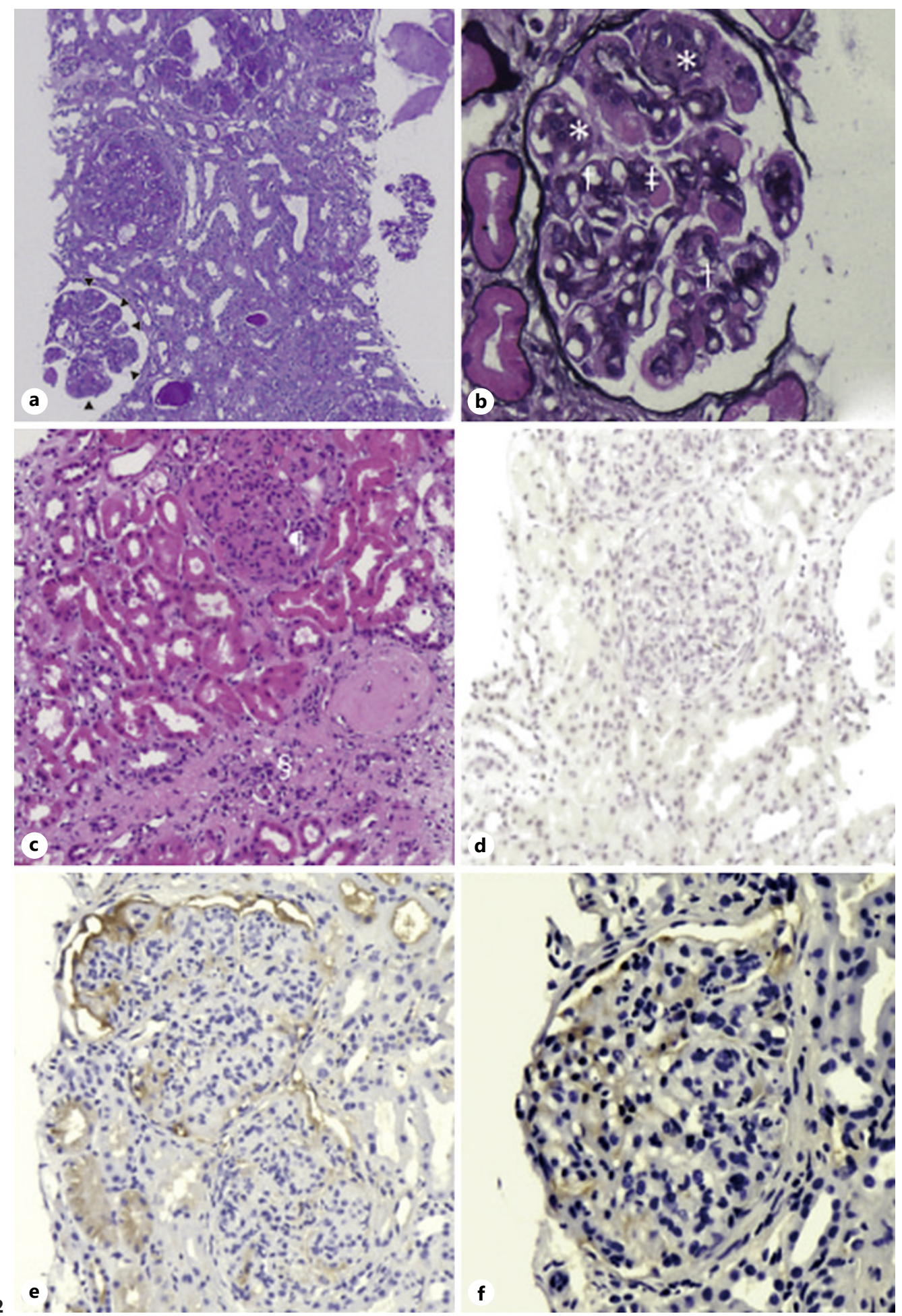

\section{Karger'}


Case Reports

in Nephrology

and Dialysis
Case Rep Nephrol Dial 2021;11:136-146

(c) 2021 The Author(s). Published by S. Karger AG, Basel www.karger.com/cnd

Shimizu et al.: Immunotactoid Glomerulopathy with Nontuberculous Mycobacterial Infection
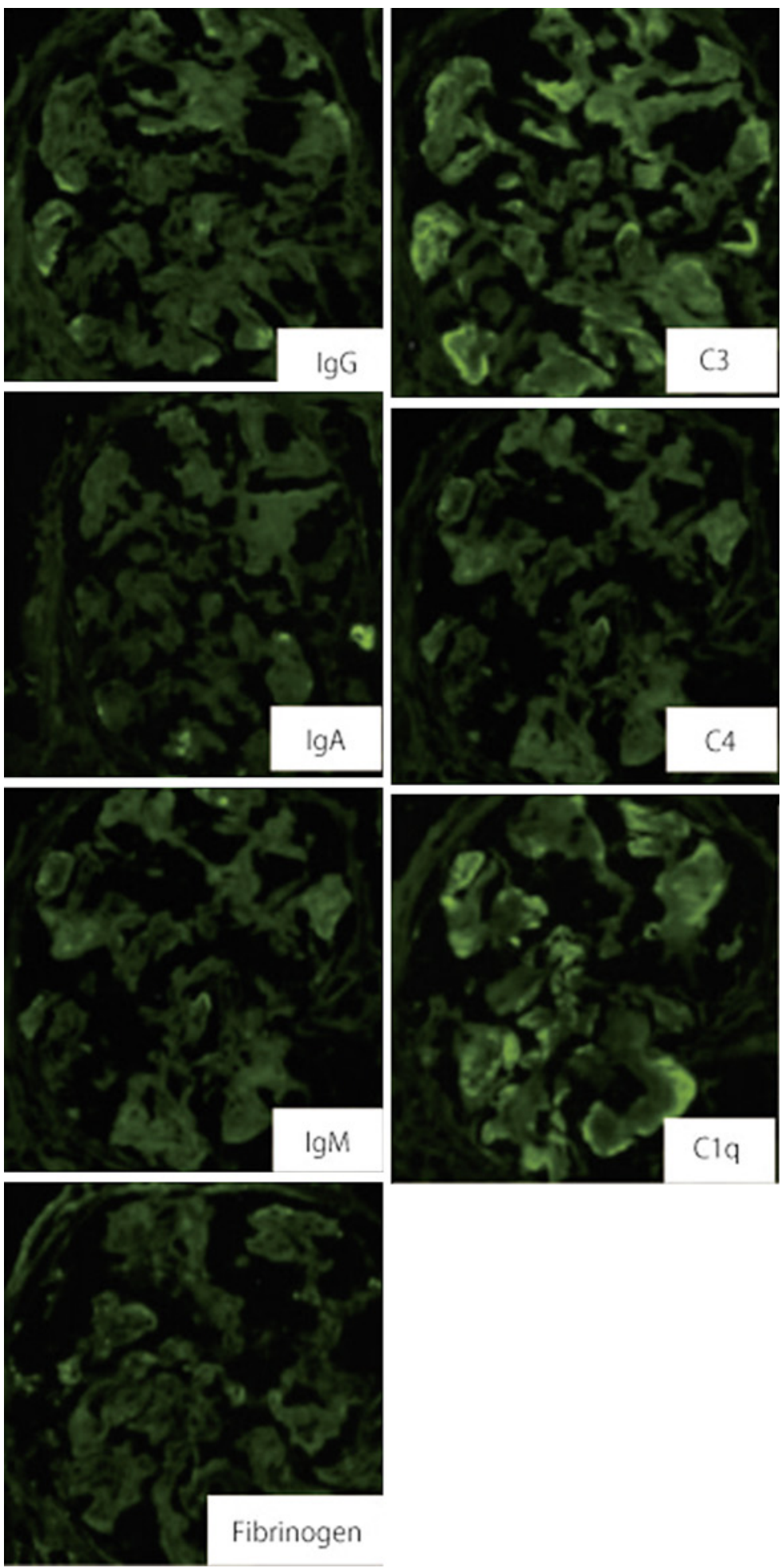

$\mathrm{Clq}$

Fig. 3. Immunofluorescence findings. Deposition of $\mathrm{C} 3$ and $\mathrm{C} 1 \mathrm{q}$ in the glomerular mesangial areas is evident and, weak linear deposition of IgG and IgM along the glomerular capillary walls is observed $(\times 200)$. Ig, immunoglobulin. 
complex-associated MPGN can arise after mycobacterial infection $[15,16]$. While most of such cases are tuberculosis, only 1 case with NTM has been reported in Japan. In this case, AA amyloid deposition was observed in the stomach, colon, and renal tissues [17]. Since the amyloid fibrils are derived from $\mathrm{N}$-terminal cleavage fragments of the hepatic acute-phase reactant serum amyloid A protein, at least 2 types of proteins from different origins can become deposited in the glomeruli [18].

A recent study by Nasr et al. [19] divided ITG into 2 groups: monoclonal ITG and polyclonal ITG. Our patient is suggested as polyclonal ITG by kappa and lambda light-chain staining (Fig. 2e, f). The IF shows C3 and C1q depositions were dominant in the mesangial area and weak signals of IgG and IgM along the capillary walls while whole signals are subtle. Although deposited types of Igs and complements follow the summarized data in Nasr's study, the cause of weak fluorescence intensity and distributive difference in glomeruli between Igs and complements are uncertain [19]. During polymerization into microtubules, it is possible that the precursor proteins were chemically or structurally modified.

ITG is defined by the glomerular deposition of microtubules that have distinct hollow centers, which can range in size from 10 to $90 \mathrm{~nm}[20,21]$. Proteomic analyses have revealed that Ig light- or heavy-chain C regions predominate in ITG [22]. The incidence of serum or urine monoclonal gammopathy is $67 \%$, and serum monoclonal $\mathrm{M}$ spike is detected $63 \%$ of patients with ITG $[23,24]$. Among the 16 patients with ITG, hematologic cancer was diagnosed in more than $35 \%$ of patients [24]. Moreover, association with paraprotein is widely discussed, and SLE or HCV infections are listed among the causal illnesses of ITG [25].

While there have been no cases of ITG associated with NTM, there has been 1 case associated with tuberculosis [26]. This 37-yr-old male patient exhibited proteinuria in the nephrotic range ( $4.8 \mathrm{~g} /$ day) and stage G3a CKD. After undergoing antitubercular treatment, proteinuria decreased to $1.1 \mathrm{~g} /$ day, but the CKD progressed to stage G4 [27]. Both patients exhibited similar responses to antibacterial treatment and clinical courses. It is difficult to prove whether mycobacterial infection per se caused ITG; however, its treatment did result in partial remission.

As direct evidence of the causal role of infectious agents has not been reported previously, a genomic fragment of $M$. intracellulare was not detected in our patient's renal biopsy specimen [15-17, 26, 27]. Considering the pathophysiology of immune complex-associated MPGN or paraprotein deposition diseases, including amyloidosis, cryoglobulinemia, and ITG massive chronic Ig production, are common. Most of the cases led to partial recovery after the treatments of the associated infection. Thus, while infection induces the formation of primary immune complexes, their mass and properties might gradually become virulent under prolonged inflammatory circumstances.

Fig. 4. Electron microscopy findings and genomic PCR. a EDDs forming mesangial interposition $(\times 6,400)$. b EDDs in the glomerular capillary walls and the paramesangial area $(\times 6,400)$. c EDDs in the subepithelial area. Foot processes over the deposits are effaced $(\times 4,600)$. d High-magnification view reveals that the EDDs are composed of microtubules with a diameter of $50 \mathrm{~nm}$. These tubules form parallel arrays $(\times 10,000)$. e Anti-DNAJB9 antibody staining of the patient's biopsy specimen. While tubules show positive signals, glomeruli do background level $(\times 200)$. f Positive control of anti-DNAJB9 antibody. Human-resected pancreas was stained with anti-DNAJB9 antibody. The exocrine glands are well stained $(\times 100)$. $\mathbf{g}$ The genomic fragment of M. intracellulare was not detected in the renal biopsy specimen. Genomic DNA was extracted from a paraffinembedded slide from the patient's renal biopsy specimen using a commercial kit. The PCR template for the positive control was provided by RIKEN BRC through the National BioResource Project of the MEXT/AMED, Japan. The $M$. intracellulare-specific PCR primers were 5'-CAG CCA GCC GAA TGT CAT CC-3' and 5'-CAA CTC GCG ACA CGT TCA CC-3'. The expected specific band was 1,070 bp [8]. EDD, electron-dense deposit; DNAJB9, anti-DnaJ homolog subfamily B member 9.

\section{Karger ${ }^{\prime \prime}$}

(For figure see next page.) 
Case Reports in Nephrology and Dialysis

\begin{tabular}{l|l}
\hline Case Rep Nephrol Dial 2021;11:136-146 \\
\hline DOI: 10.1159/000515583 & $\begin{array}{l}\text { @ 2021 The Author(s). Published by S. Karger AG, Basel } \\
\text { www.karger.com/cnd }\end{array}$ \\
\hline
\end{tabular}

Shimizu et al.: Immunotactoid Glomerulopathy with Nontuberculous Mycobacterial Infection

EM provides useful diagnostic information in nearly half of native renal biopsies [27]. It is impossible to differentiate ITG from immune complex-associated MPGN without EM findings. Ultrastructural examination of EDDs was essential for precise diagnosis in this case.
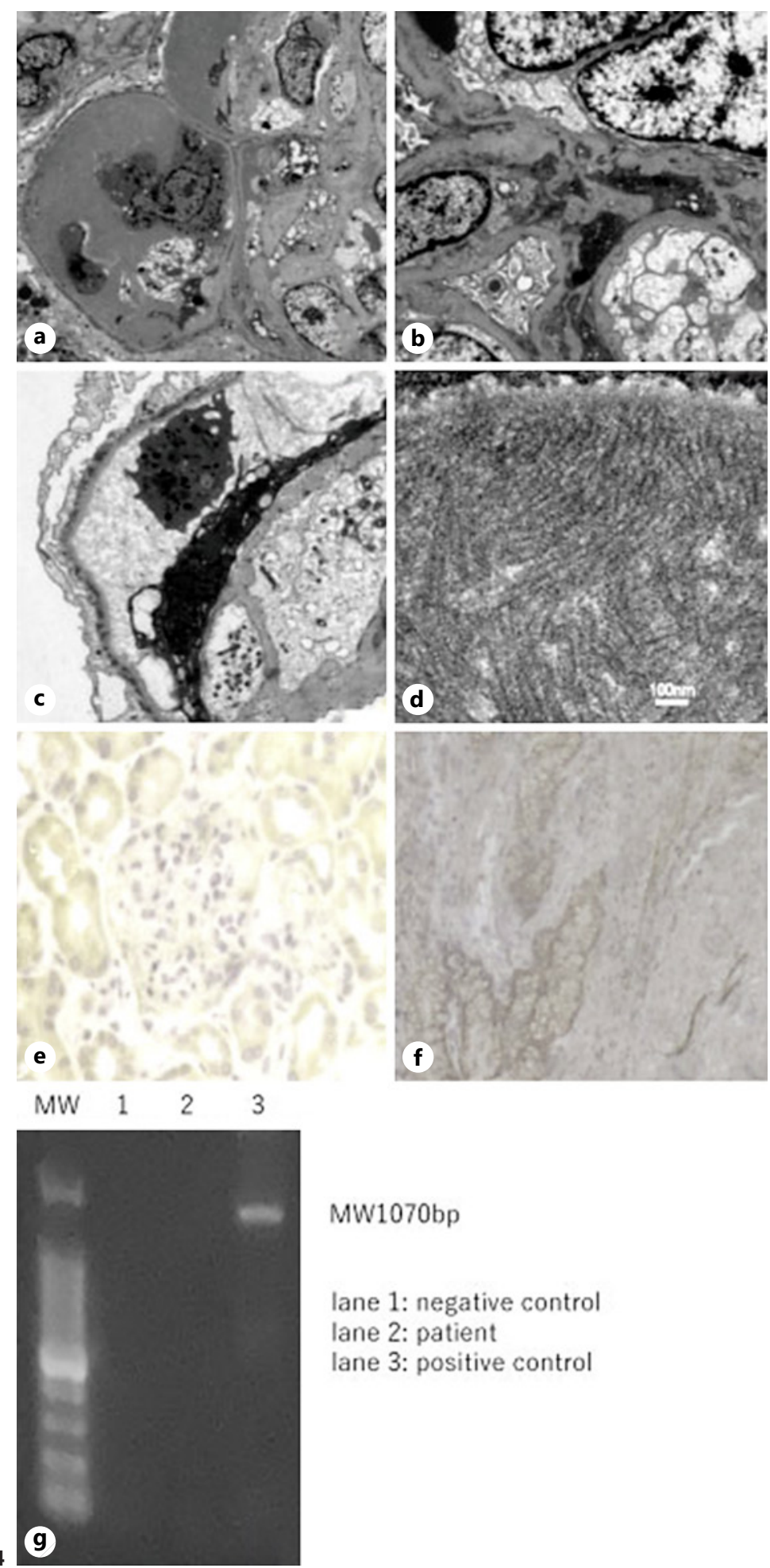

MW1070bp

lane 1: negative control lane 2: patient

lane 3: positive control

\section{Karger's}




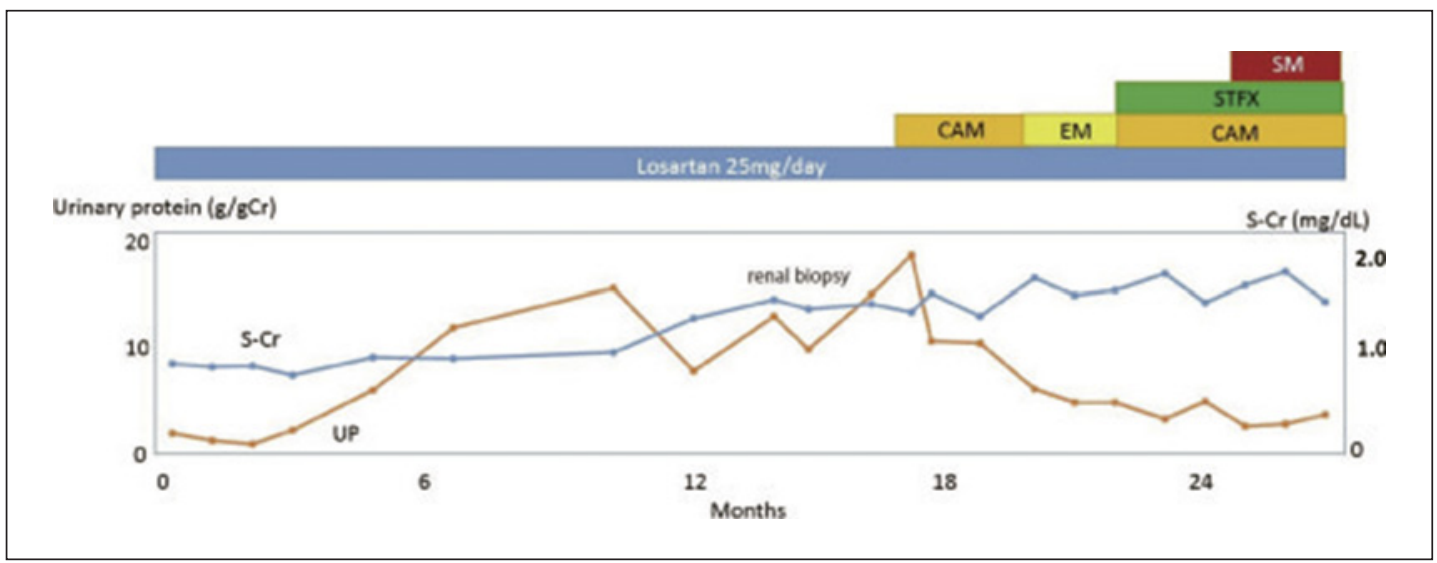

Fig. 5. Clinical course of the patient. CAM, clarithromycin; EM, erythromycin; STFX, sitafloxacin; SM, streptomycin.

\section{Conclusion}

Our patient is the first association of ITG with NTM. Although the relationships between ITG and lymphoproliferative disorders are weighted for discussion, mycobacterial infection including tuberculosis and NTM should be considered as a causal disease of ITG. ITG is a possible outcome of Ig-associated MPGN.

\section{Acknowledgements}

We are indebted to the nephrologists, nursing staff, staff in the laboratory of pathology, and the patient at the Juntendo University Shizuoka Hospital for their collaboration and participation in this study. Ayumi Kurusu achieved excellent performance for immunohistochemistry.

\section{Statement of Ethics}

This study was approved by the Ethics Committee of the Juntendo University Shizuoka Hospital. Written informed consent was obtained from the patient.

\section{Conflict of Interest Statement}

The authors have no conflicts of interests to declare.

\section{Funding Sources}

This study was supported by JSPS KAKENHI (grant numbers 26461238 and 17K09039). Shizuoka Medical Research Center for Disaster, Juntendo University, is supported by the MEXT-Supported Program for the Strategic Research Foundation at Private Universities, 2015-2019 and Juntendo University. The authors have no conflicts of interest to declare. 


\section{Case Reports in Nephrology and Dialysis}

\begin{tabular}{l|l}
\hline Case Rep Nephrol Dial 2021:11:136-146 \\
\hline DOI: 10.1159/000515583 & $\begin{array}{l}\text { @ 2021 The Author(s). Published by S. Karger AG, Basel } \\
\text { www.karger.com/cnd }\end{array}$ \\
\hline
\end{tabular}

Shimizu et al.: Immunotactoid Glomerulopathy with Nontuberculous Mycobacteria Infection

\section{Author Contributions}

Y.S., K.W., H.I., C.K., S.S., T.O., R.W., and T.I. were responsible for the clinical management of the patient and preparing the draft version of this manuscript. H.M. presented a specimen of human-resected pancreas for positive control of anti-DNAJB9 antibody staining. Y.T. and Y.S. contributed to the review of the literature. All authors participated in the writing of the manuscript and read and approved the final version.

\section{References}

1 West CD. Idiopathic membranoproliferative glomerulonephritis in childhood. Pediatr Nephrol. 1992;6: 96-103.

2 Rennke HG. Secondary membranoproliferative glomerulonephritis. Kidney Int. 1995;47:643-56.

3 Salvadori M, Rosso G. Reclassification of membranoproliferative glomerulonephritis: identification of a new GN: C3GN. World J Nephrol. 2016;5:308-20.

4 Sethi S, Fervenza FC. Membranoproliferative glomerulonephritis: pathogenetic heterogeneity and proposal for a new classification. Semin Nephrol. 2011;31:341-8.

5 Bomback AS, Appel GB. Pathogenesis of the C3 glomerulopathies and reclassification of MPGN. Nat Rev Nephrol. 2012;8:634-42.

6 Nasr SH, Vrana JA, Dasari S, Bridoux F, Fidler ME, Kaaki S, et al. DNAJB9 is a specific immunohistochemical marker for fibrillary glomerulonephritis. Kidney Int Rep. 2017;3:56-64.

7 DNAJB9. The human protein atlas. Tissue expression of DNAJB9 - Primary data: The Human Protein Atlas. Tissue expression of DNAJB9 - Staining in pancreas - The Human Protein Atlas. https//www.Proteinatlas. org/ENS00000128590-DNAJB9/tissue.

8 Joh K. Pathology of glomerular deposition diseases. Pathol Int. 2007;57:551-65.

9 Nishimori K, Eguchi M, Nakaoka Y, Onodera Y, Ito T, Tanaka K. Distributin of IS901 in strains of mycobacterium avium complex from swine by using IS901-detecting primers that discriminate between M. avium and mycobacterium intracellulare. J Clin Microbiol. 1995;33:2102-6.

10 Smith KD, Alpers CE. Pathogenic mechanisms in membranoproliferative glomerulonephritis. Curr Opin Nephrol Hypertens. 2005;14:396-403.

11 Ohara S, Kawasaki Y, Takano K, Isome M, Nozawa R, Suzuki H, et al. Glomerulonephritis associated with chronic infection from long-term central venous catheterization. Pediatr Nephrol. 2006;21:427-9.

12 Rodrigues VL, Otoni A, Voieta I, Antunes CM, Lambertucci JR. Glomerulonephritis in schistosomiasis mansoni: a time to reappraise. Rev Soc Bras Med Trop. 2010;43:638-42.

13 Khan MA, Akhtar M, Taher SM. Membranoproliferative glomerulonephritis in a patient with primary Sjögren's syndrome. Report of a case with review of the literature. Am J Nephrol. 1988;8:235-9.

14 Sethi S, Zand L, Leung N, Smith RJ, Jevremonic D, Herrmann SS, et al. Membranoproliferative glomerulonephritis secondary to monoclonal gammopathy. Clin J Am Soc Nephrol. 2010;5:770-82.

15 Pecchini F, Bufano G, Ghiringhelli P. Membranoproliferative glomerulonephritis secondary to tuberculosis. Clin Nephrol. 1997;47:63-4.

16 Ram R, Sandeep P, Sridhar AV, Rukumangadha N, Sivakumar V. Membranoproliferative glomerulonephritis and Pott's disease. Clin Kidney J. 2014;7:391-3.

17 Tsuji K, Arai H, Furusu A, Torigoe K, Tokuyama A, Muraya Y, et al. A case of membranoproliferative glomerulonephritis and AA amyloidosis complicated with pulmonary nontuberculous mycobacterial infection. CEN Case Rep. 2015;4:24-30.

18 Westermark GT, Fändrich M, Westermark P. AA amyloidosis: pathogenesis and targeted therapy. Annu Rev Pathol. 2015;10:321-44.

19 Nasr SH, Kudose SS, Said SM, Santoriello D, Fidler ME, Williamson SR, et al. Immunotactoid glomerulopathy is a rare entity with monoclonal and polyclonal variants. Kidney Int. 2020;S0085-2538(20):30953-4.

20 Herrera GA, Turbat-Herrera EA. Renal diseases with organized deposits: an algorithmic approach to classification and clinicopathologic diagnosis. Arch Pathol Lab Med. 2010;134:512-31.

21 Motwani SS, Herlitz L, Monga D, Jhaveri KD, Lam AQ; American Society of Nephrology Onco-Nephrology Forum. Paraprotein-related kidney disease: glomerular diseases associated with paraproteinemias. Clin J Am Soc Nephrol. 2016;11:2260-72.

22 Sethi S, Theis JD, Vrana JA, Fervenza FC, Sethi A, Qian Q, et al. Laser microdissection and proteomic analysis of amyloidosis, cryoglobulinemic GN, fibrillary GN, and immunotactoid glomerulopathy. Clin J Am Soc Nephrol. 2013;8:915-21.

23 Rosenstock JL, Markowitz GS, Valeri AM, Sacchi G, Appel GB, D’Agati VD. Fibrillary and immunotactoid glomerulonephritis: distinct entities with different clinical and pathologic features. Kidney Int. 2003;63:1450-61. 
Case Reports

in Nephrology

and Dialysis
Case Rep Nephrol Dial 2021;11:136-146

\begin{tabular}{l|l}
\hline DOI: $10.1159 / 000515583$ & (c) 2021 The Author(s). Published by S. Karger AG, Basel
\end{tabular} www.karger.com/cnd

Shimizu et al.: Immunotactoid Glomerulopathy with Nontuberculous Mycobacteria Infection

24 Nasr SH, Fidler ME, Cornell LD, Leung N, Cosio FG, Sheikh SS, et al. Immunotactoid glomerulopathy: clinicopathologic and proteomic study. Nephrol Dial Transplant. 2012;27:4137-46.

25 Herrera GA, Ojemakinde KO, Turbat-Herrera EA, Gu X, Zeng X, Iskandar SS. Immunotactoid glomerulopathy and cryoglobulinemic nephropathy: two entities with many similarities. A unified conceptual approach. Ultrastruct Pathol. 2015;39:270-80.

26 Gupta A, Khaira A. Immunotactoid glomerulopathy and tuberculosis: a novel association. Nefrologia. 2011;31: 369-71.

27 Haas M. A reevaluation of routine electron microscopy in the examination of native renal biopsies. J Am Soc Nephrol. 1997;8:70-6. 